\title{
Peristiwa Ketidakpastian Pada Pelaksanaan Tol Layang A.P.Pettarani Seksi III Kota Makassar
}

\author{
Rebecca S. Tambunan ${ }^{\star 1}$ Helen. A.I. Sopacua ${ }^{\star 2}$ Josefine. E. Latupeirissa ${ }^{\star 3}$ \\ *1 Mahasiswa Program Studi Teknik Sipil, Universitas Kristen Indonesia Paulus, Makassar, Indonesia \\ rebeccatambunan07@gmail.com \\ *2,3 Dosen Program Studi Teknik Sipil, Universitas Kristen Indonesia Paulus, Makassar, Indonesia \\ sopacuahelen@gmail.com dan josefine ernestine@yahoo.com
}

\begin{abstract}
ABSTRAK
Jalan Tol Layang A. P. Pettarani merupakan proyek kontruksi yang memakan waktu cukup lama dan kompleks sehingga dapat menimbulkan ketidakpastian yang akhirnya akan memunculkan berbagai macam risiko. Dampak risiko tersebut dapat mempengaruhi produktivitas, kinerja/performance, kualitas dan anggaran biaya proyek. Kesuksesan proyek konstruksi sangat tergantung dari kemampuan manager proyek dalam mengelola risiko yang terjadi. Manajemen risiko meliputi langkahlangkah yang terkait usaha pelaksanaan perencanaan manajemen risiko, identifikasi, tanggapan, dan monitoring serta pengawasan pada suatu proyek. Oleh karena itu, dilakukan penelitian yang bertujuan untuk mengidentifikasi, menganalisis, serta mengetahui respon risiko-risiko yang dominan terjadi, dengan menggunakan metode pengumpulan data primer berupa kuisioner dengan menggunakan skala likert, matriks Probability x Impact, Risk Map dan wawancara, dimana pada penelitian ini didapatkan sebelas variabel risiko yang dominan terhadap proyek ini.
\end{abstract}

Kata Kunci : Proyek konstruksi, Ketidakpastian, Risiko

\begin{abstract}
The A. P. Pettarani elevated toll road is a project construction which is takes a long time and complex that can be create uncertainties that will eventually present a wide range of risks. The impact of these risks can affect productivity, performance, quality, and project cost budgets. The success of the construction project depends lagerly on the ability of the project manager to manage the risks involved. Risk management includes the steps involved in executing risk management planning, identification, responses, reaction, and monitoring of a project. Therefore, research was conducted to identify, analyze, and to knowing dominant risks responses, using the primary data collection method of questionnaire using the likert scale, probability $\mathrm{x}$ impact matrix, risk map, and interview, which is in this research have eleven dominant risk variables found in the project.
\end{abstract}

Keywords: Construction project, Uncertainties, Risk 


\section{PENDAHULUAN}

Propinsi Sulawesi Selatan adalah salah satu propinsi di Indonesia Timur yang sedang giat- giatnya membangun karena mengalami kemajuan dalam berbagai aspek. Letaknya yang strategis karena menjadi tempat transit dari daerah-daerah di Indonesia bagian Barat ke daerah-daerah di Indonesia bagian Timur. Untuk memperlancar transportasi maka pemerintah Kota Makassar mengadakan pembangunan Jalan Tol layang A. P. Pettarani Seksi III.

Proyek jalan tol layang dapat dikatakan sebagai proyek yang berisiko tinggi mengingat besarnya bobot pekerjaan serta tingginya struktur yang akan dibangun nantinya. Proses konstruksi proyek ini memakan waktu yang cukup lama dan kompleks sehingga dapat menimbulkan ketidakpastian yang akhirnya akan memunculkan berbagai macam risiko. Risiko adalah faktor-faktor yang dapat mempengaruhi pencapaian tujuan, sehingga terjadinya konsekuensi yang tidak diinginkan. Oleh karena itu, dapat dikatakan Risiko muncul karena ketidakpastian. Dampak risiko dapat mempengaruhi produktivitas, kinerja/performance, kualitas dan anggaran biaya proyek. Salah satu risiko yang terjadi adalah timbulnya kemacetan disekitar lokasi proyek karena lokasi proyek yang terletak pada pemukiman padat penduduk dan berdekatan dengan lingkungan perkantoran dan beberapa pusat perbelanjaan, dan terjadinya demo besar- besaran dibeberapa wilayah di Indonesia beberapa waktu lalu termasuk wilayah Makassar yang berdampak terhadap kerusakan beberapa material yang ada dilapangan akibat kegiatan demonstrasi massa. Selain itu juga terdapat risiko pada saat proses pelaksanaan proyek misalnya, pada saat pengecoran.

Tujuan penelitian ini adalah untuk mengidentifikasi risiko selama pekerjaan proyek, untuk menganalisis risiko yang paling dominan terjadi, dan untuk mengetahui respon riisko dari risiko paling dominan. Dalam dunia nyata selalu terjadi perubahan yang sifatnya dinamis, hingga selalu terdapat ketidakpastian. Risiko timbul karena adanya ketidakpastian, dan risiko akan menimbulkan konsekuensi tidak menguntungkan. Jika risiko tersebut menimpa suatu proyek, maka proyek tersebut bisa mengalami kerugian yang signifikan. Dalam beberapa situasi, risiko tersebut bisa mengakibatkan terbengkalainya proyek tersebut. Karena itu risiko penting untuk dikelola.

Manajemen risiko proyek mencakup proses melakukan perencanaan manajemen risiko, identifikasi, analisa, perencanaan respon, dan pemantauan dan pengendalian proyek. Dengan demikian melalui manajemen risiko akan diketahui metode yang tepat untuk menghindari/mengurangi besarnya kerugian yang diderita akibat risiko.
Tahapan dalam manajemen risiko, yaitu perencanaan, penilaian (identifikasi , analisa, dan pengendalian risiko), penanganan, dan pemantauan.

Beberapa penelitian sejenis yaitu Ismiyati et.al menganalisis risiko-risiko yang berpotensi terjadi pada masa konstruksi perpanjangan dermaga log dan metode penanganan yang tepat pada pelaksanaan Pekerjaan Perpanjangan Dermaga Log. Hasil penelitian fenomena eksternal yang tidak terprediksi, seperti elevasi pasang surut yang melebihi rencana sehingga berdampak pada perubahan desain dan metode pelaksanaan merupakan risiko berkategori tinggi berpengaruh terhadap keterlambatan proyek [1].

Supriono menganalisis factor resiko yang mempengauhi keterlambatan pembangunan proyek infrastruktur perdesaan berdasarkan waktu perencanaan. Hasil penelitian keterlambatan pengiriman material dengan nilai dan kerusakan peralatan mesin , serta hujan merupakan factor yang paling dominan dalam keterlambatan pembangunan proyek infrastruktur perdesaan [2].

Latupeirissa et.al menganalisis persepsi tentang Contingency Cost kontraktor di Indonesia, Hasil penelitian masih tersedia ruang yang cukup besar untuk melakukan peninjauan 47 actor 47 serta perbaikan dalam pemahaman tentang contingency cost proyek sebagai suatu sarana untuk mengantisipasi risiko [3].

Lokobal et.al mengidentifikasi setiap risiko yang dihadapi oleh kontraktor. Hasil penelitian aspek manajemen pengendalian dan produksi, aspek manajemen sumber daya manusia dan 47actor budaya, aspek material dan peralatan, aspek dan keuangan, aspek perencanaan, aspek cuaca dan pengawasan, aspek harga dan anggaran biaya, dan aspek Kesehatan Dan Keselamatan Kerja (K3) [4].

Rustandi dengan tujuan penelitian mendapatkan 47actor risiko, yang paling dominan mempengaruhi pembangunan proyek daerah irigasi bending. Hasil penelitian risiko yang paling memiliki probabilitas dan dampak terbesar adalah 47actor risiko ketidakpastian kondisi lapangan dengan nilai 47actor risiko 0,83 [5].

Hartono et.al menggunakan metode AHP untuk menganalisis risiko konstruksi struktur atas pembangunan proyek. Hasil penelitian kinerja subkontraktor yang buruk merupakan risiko paling besar $(34,1 \%)$ disusul kemudian pengaturan dan penundaan jadwal $(17,56 \%)$ produktivitas tenaga kerja tidak sesuai spesifikasi $(11,45 \%)$, cuaca yang tidak menentu $(8,11 \%)$, terlambatnya pemesanan material $(7,41 \%)$ serta terlambatnya pengiriman alat $(5,32 \%)[6]$. 


\section{METODOLOGI PENELITIAN}

\section{Lokasi dan Waktu Penelitian}

Lokasi penelitian dilakukan pada proyek konstruksi Jalan Tol Layang A.P. Pettarani. Penelitian yang dilakukan adalah mengidentifikasi risiko dan menganalisa risiko yang paling dominan untuk terjadi.

\section{Tahap Pengumupulan Data}

Pengumpulan data berdasarkan sumber data dan metode pengumpulan data maka dibagi menjadi

Data primer merupakan data yang dicari dan dikumpulkan dalam penelitian dengan cara wawancara serta memberikan kuisioner kepada responden.

\section{Metode Survei}

Dalam penelitian ini metode survei yang digunakan adalah wawancara secara langsung menggunakan kuesioner untuk mendapatkan data-data primer.

\section{Sampel}

Jumlah sampel yang diambil akan memberikan dampak keakuratan hasil akhir perhitungan. Semakin banyak sampel yang diambil dari suatu populasi maka kemungkinan keakuratan hasil perhitungan akan semakin baik

\section{Teknik Analisis Data}

Dalam hal ini pengolahan data-data hasil survei dalam bentuk numerik dan akan dianalisis dengan rumus empirik statistika-matematis. Adapun tahapantahapan teknik analisis data dijelaskan sebagai berikut:

a. Identifikasi risiko dilakukan melalui studi literatur, observasi dengan menyebarkan kuisioner survey pendahuluan pada responden yang sudah terpilih dengan memilih jawaban relevan atau tidak relevan. Jika responden menjawab relevan pada beberapa pilihan risiko, maka risiko tersebut nantinya akan dimasukkan ke dalam form kuisioner tahap selanjutnya.

b. Analisa risiko dilakukan melalui Penyebaran kuisioner dari hasil identifikasi risiko, Penilaian (assessment) tingkat risiko terhadap frekuensi risiko yang terjadi dan dampak yang ditimbulkan dari risiko tersebut, Penggambaran hasil dari penilaian (assessment) kedalam diagram matriks berdasarkan frekuensi dan dampak, dan Wawancara.

c. Proses pengukuran risiko dengan cara memperkirakan frekuensi terjadinya suatu risiko dan dampak dari risiko. Skala yang digunakan dalam mengukur potensi risiko terhadap frekuensi dan dampak risiko adalah skala likert dengan menggunakan rentang angka 1 sampai dengan 5 .

\section{ANALISIS DAN PEMBAHASAN}

Pada matriks probabilitas dan dampak, setelah memberikan skor untuk kemungkinan dan dampak dari kategori risiko yang diidentifikasi pada kuisioner maka dilanjutkan dengan mengalikan dua variabel, kemudian hasilnya dapat dilihat pada matriks probability $\mathrm{x}$ impact untuk mengetahui seberapa besar risikonya. Setelah mengetahui tingkatan Probability x Impact dari suatu risiko, dapat diplotkan pada matriks frekuensi dan dampak untuk mengetahui strategi mengahadapi risiko tersebut. Menurut Hanafi (2006), untuk memilih respon risko yang akan digunakan untuk menangani risiko-risiko yang telah terjadi, dapat digunakan Risk Map. Risk Map dapat dilihat pada Gambar 2.

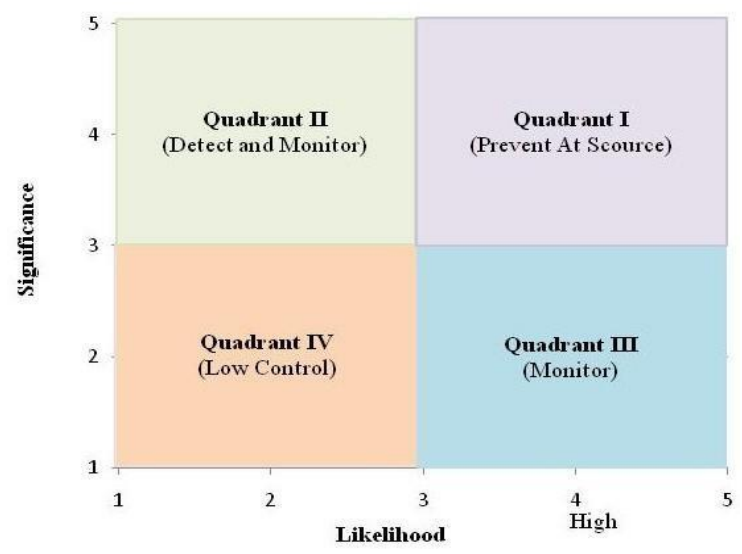

Gambar 2. Risk Map

\section{Respon Risiko}

Untuk mengetahui bagaimana respon yang dilakukan pada suatu risiko yang dominan dilakukan wawancara respon risiko ada responden yang telah terpilih sebelumnya. Data penelitian diperoleh melalui kuisioner dan In Depth Interview yang dilakukan terhadap responden dalam penelitian yang dalam hal ini adalah Project Manager, Site Engineering Manager, Site Operational Manager. Para responden memberikan informasi hanya pada masalah-masalah yang berkaitan dengan bidang yang mereka kuasai masing-masing. Data-data yang didapat dalam interview tersebut adalah data mengenai profil responden, risiko-risiko yang relevan pada proyek konstruksi Tol Layang A. P. Pettarani, frekuensi risiko yang terjadi, serta dampak risiko tersebut terhadap biaya dan waktu. Data lain yang didapat adalah respon yang dilakukan terhadap risikorisiko yang dominan.

a. Identifikasi risiko

Proses identifikasi risiko adalah dengan memberikan form kuisioner untuk diisi oleh responden. Form 
kuisioner yang diberikan terdapat pada lampiran pertama. $\quad$ Para pada kolom relevan maupun tidak relevan. Dalam hal ini keterangan relevan adalah variable risiko tersebut pernah terjadi atau mungkin akan terjadi diwaktu yang akan datang, sedangkan tidak relevan adalah variabel risiko tersebut tidak pernah terjadi atau tidak mungkin terjadi diwaktu yang akan datang pada proyek pembangunan Jalan Tol Layang A. P. Pettarani. Project Manager memberikan informasi pada tenaga kerja, risiko kontraktual, dan risiko manajemen. Site Engineering Manager (SEM) memberikan informasi tentang risiko-risiko pada material dan peralatan serta risiko desain dan teknologi, sedangkan Site Operational Manager (SOM) memberi informasi tentang risiko-risiko dibidang force majeure dan risikorisiko pada saat pelaksanaan di lapangan. Pada studi literature yang telah dilakukan didapatkan 95 variabel risiko yang biasa terjadi pada proyek pembangunan konstruksi. Setelah dilakukan survey kuisioner didapatkan 47 variabel risiko yang terjadi pada proyek pembangunan Jalan Tol Layang A. P. Pettarani ini. Hal tersebut dikarenakan item- item risiko yang memiliki jawaban 'tidak relevan' pada form kuisioner identifikasi risiko dieliminasi. Setelah mendapatkan identifikasi risiko yang relevan pada proyek Jalan Tol Layang A. P. Pettarani, dilakukan survey kuisioner tahapkedua yaitu kuisioner frekuensi risiko dan dampak risiko kepada responden-responden yang telah terpilih sebelumnya tentang frekuensi (kali kejadian) risiko-risiko dan dampak yang didapat terhadap biaya maupun terhadap waktu. Proses ini dilakukan dengan memberikan form kuisioner kepada responden untuk diisi.

\section{b. Analisa Risiko}

\section{Analisa Risiko berdasarkan Probability $\mathbf{x}$}

Impact terhadap Biaya Pada saat dilakukan survey kuisioner frekuensi risiko dan dampak risiko kepada responden, metode yang digunakan ialah skala likert untuk mengukur probability atau frekuensi kejadian variabel risiko yang relevan ada proyek Jalan Tol Layang A. P. Pettarani ini. Begitu pula untuk mengukur impact dari kejadian variabel risiko juga digunakan skala likert. Dimana skala likert untuk mengukur probability atau frekuensi, yaitu:

$\begin{array}{ll}\text { Sangat jarang (SS) } & =1 \\ \text { Jarang (J) } & =2 \\ \text { Cukup (C) } & =3 \\ \text { Sering (S) } & =4 \\ \text { Sangat Sering (SS) } & =5\end{array}$

Keterangan skala pada Probability atau frekuensi terjadinya risiko adalah sebagai berikut:

Sangat Jarang $(\mathrm{SJ})=<3$ kali kejadian Jarang $(\mathrm{J})$ $=3-5$ kali kejadian Cukup $(\mathrm{C}) \quad=6-7$ kali kejadian Sering (S) $\quad=8-10$ kali kejadian Sangat Sering (SS) $=>10$ kali kejadian
Kriteria penetapan skala probability atau frekuensi terjadinya risiko ini didapatkan dari referensi atau studi literatur pada penelitian sejenis sebelumnya. Sedangkan skala likert untuk mengukur impact terhadap biaya, yaitu:

$\begin{array}{ll}\text { Sangat Kecil (SK) } & =1 \\ \text { Kecil (K) } & =2 \\ \text { Sedang (S) } & =3 \\ \text { Besar (B) } & =4 \\ \text { Sangat Besar (SB) } & =5\end{array}$

Dengan keterangan skala pada impact terhadap biaya sebagai berikut:

$\begin{array}{ll}\text { Sangat Kecil (SK) } & =<900 \text { Juta } \\ \text { Kecil (K) } & =900-40 \text { Milyar } \\ \text { Cukup (C) } & =40-80 \text { Milyar } \\ \text { Besar (B) } & =80-160 \text { Milyar } \\ \text { Sangat Besar (SB) } & =>160 \text { Milyar }\end{array}$

Kriteria penetapan skala pada impact terhadap biaya ini didapat berdasarkan referensi atau studi literatur dari penelitian sejenis sebelumnya. Kriteria tersebut dibuat berdasarkan nilai biaya kontingensi dari nilai kontrak proyek Jalan Tol Layang A. P. Pettarani. Dimana nilai kontrak proyek tersebut adalah sebesar kurang lebih 1,6 Triliun. Sedangkan besar biaya kontingensi pada proyek tersebut diambil sebesar $10 \%$ dari nilai kontrak. Pengambilan nilai biaya kontingensi $10 \%$ ini dikarenakan tidak ada rumusan yang baku untuk menentukan besar angka biaya kontingensi, yang pada umumnya berkisar $10 \%-13 \%$. Apabila nilai biaya kontingensi adalah sebesar $10 \%$ terhadap nilai kontrak, maka biaya kontingensi adalah sebesar 160 Milyar rupiah, yang kemudian skala nilai biaya kontingensi tersebut dibagi dalam 5 interval.

Setelah diketahui nilai skala probability serta nilai skala impact dari kejadian variabel risiko erhadap biaya yang didapat dari hasil kuisioner kepada responden pada proyek pembangunan Jalan Tol Layang A. P. Pettarani, kemudian dilanjutkan dengan analis risiko yang menggunakan tabel Probability $\mathrm{x}$ Impact $(\mathrm{P} \times \mathrm{I})$. Proses pengerjaan table Probability $\mathrm{x}$ Impact adalah dengan ara memasukkan nilai skala probability dan memasukkan nilai skala impact terhadap biaya yang telah didapat dari hasil survey kuisioner, kemudian dilanjutkan dengan mengalikan skala pada kolom probability dan skala pada kolom impact. Setelah itu didapat nilai yang dijadikan acuan untuk mengetahui risiko-risiko mana saja yang kemungkinan terjadinya besar dan menimbulkan dampak yang signifikan terhadap biaya.

\section{Analisa Risiko berdasarkan Impact}

Analisa risiko berdasarkan impact terhadap waktu ini tidak berbeda jauh dengan analisa risiko berdasarkan impact terhadap biaya. Peneliti juga menggunakan skala likert untuk mengukur 
probability maupun mengukur impact terhadap waktu. Pengukuran skala probability sama dengan yang telah dijelaskan pada bab sebelumnya, sedangkan skala likert untuk mengukur impact terhadap waktu, yaitu:

$\begin{array}{ll}\text { Sangat Kecil (SK) } & =1 \\ \text { Kecil (K) } & =2 \\ \text { Sedang (S) } & =3 \\ \text { Besar (B) } & =4 \\ \text { Sangat Besar (SB) } & =5\end{array}$

Dengan keterangan skala pada impact terhadap waktu sebagai berikut: Sangat Kecil (SK) $=0-20$ Hari Kecil $(\mathrm{K}) \quad=21-40$ Hari Cukup $(\mathrm{C})$ $=41-60$ Hari Besar $(B) \quad=61-80$ Hari Sangat Besar $(\mathrm{SB})=81-100$ Hari

Kriteria penetapan skala impact terhadap waktu ini didapat berdasarkan referensi atau studi literatur dari penelitian sejenis sebelumnya. Kriteria tersebut didasarkan pada denda keterlambatan sebesar $1 \%$ dari nilai kontrak proyek perhari. Denda keterlambatan pada proyek ini adalah sebesar 1,6 Milyar per hari. Berdasarkan nilai biaya kontingensi yang sebesar $10 \%$ dari nilai kontrak, yaitu sebesar kurang lebih 1,6 triliun rupiah, didapatkan 100 hari keterlambatan untuk mencapai nilai sebesar nilai biaya kontingensi, kemudian skala nilai jumlah hari keterlambatan yang didapatkan diatas dibagi dalam 5 interval.
Setelah diketahui nilai skala probability serta nilai skala impact dari kejadian variabel risiko terhadap waktu yang didapat dari hasil kuisioner kepada responden pada proyek pembangunan Jalan Tol Layang A. P. Pettarani, kemudian dilanjutkan dengan analisa risiko yang menggunakan tabel Probability $x$ Impact $(\mathrm{P} \times \mathrm{I})$. Proses pengerjaan tabel Probability $\mathrm{x}$ Impact adalah dengan cara memasukkan nilai skala impact terhadap waktu yang telah didapat dari hasil survey kuisioner, kemudian dilanjutkan dengan mengalikan skala pada kolom probability dan skala pada kolom impact. Setelah itu didapat nilai yang dijadikan acuan untuk mengetahui risiko-risiko mana saja yang kemungkinan terjadinya besar dan menimbulkan dampak yang signifikan terhadap waktu.

Pada proyek pembangunan Jalan Tol Layang A. P. Pettarani ini risiko kerusakan peralatan mesin dan perlengkapan proyek serta kerusakan yang terjadi di daerah sekitar pada saat proses pengerjaan bore pile, pile cap, kolom, maupun box girder yang mempunyai nilai paling besar pada tabel Probability $x$ Impact terhadap biaya. Sedangkan risiko yang mempunyai nilai paling besar pada tabel Probability $x$ Impact terhadap waktu adalah adanya perubahan desain.

Tabel 1. Probability $X$ Impact terhadap biaya dengan risiko yang terpilih

\begin{tabular}{lll}
\hline No & Variabel risiko & P x I \\
\hline $\mathbf{2}$ & A9. Demonstrasi & 9 \\
$\mathbf{3}$ & B9. Kerusakan peralatan mesin dan perlengkapan proyek & 12 \\
$\mathbf{4}$ & C5. Tenaga kerja tidak terampil & 9 \\
$\mathbf{5}$ & C6. Kurang tersedianya jumlah tenaga kerja di lapangan & 9 \\
$\mathbf{6}$ & C7. Produktivitas tenaga kerja yang rendah & 9 \\
$\mathbf{7}$ & E1. Timbulnya kemacetan di sekitar lokasi proyek & 8 \\
$\mathbf{8}$ & E11. Kerusakan yang terjadi di daerah sekitar pada saat proses pengerjaan bore pile, pile cap, & 12 \\
$\mathbf{9}$ & kolom, pier head, box girder. & \\
$\mathbf{1 0}$ & F2. ADanya perubahan desain & 8 \\
& G14. Ketepatan pekerjaan konstruksi & 9
\end{tabular}

Tabel 2. Probability $\mathrm{x}$ Impact terhadap waktu dengan risiko yang terpilih

\begin{tabular}{lll}
\hline No & Variabel risiko & P x I \\
\hline $\mathbf{2}$ & A6. Tersambar petir & 4 \\
$\mathbf{3}$ & A7. Kebakaran & 4 \\
$\mathbf{4}$ & A9. Demonstrasi & 9 \\
$\mathbf{5}$ & B9. Kerusakan peralatan mesin dan perlengkapan proyek & 16 \\
$\mathbf{6}$ & C5. Tenaga kerja tidak terampil & 9 \\
$\mathbf{7}$ & C6. Kurang tersedia jumlah tenaga kerja lapangan & 9 \\
$\mathbf{8}$ & C7. Produktivitas tenaga kerja yang rendah & 9 \\
$\mathbf{9}$ & E1. Timbulnya kemacetan di sekitar lokasi proyek & 16 \\
$\mathbf{1 0}$ & E6. Titik bore pile yang tidak tepat & 9 \\
$\mathbf{1 1}$ & E11. Kerusakan yang terjadi di daerah sekitar pada saat proses pengerjaan bore pile, pile cap, & 12 \\
& pier head, kolom, dan box girder & 20 \\
$\mathbf{1 2}$ & F2. Adanya perubahan desain & 9
\end{tabular}


Respon risiko pada risiko kerusakan peralatan mesin dan perlengkapan proyek serta kerusakan yang terjadi di daerah sekitar pada saat proses pengerjaan bore pile, pile cap, kolom, maupun box girder yang merupakan risiko yang mempunyai nilai paling besar pada tabel Probability $\mathrm{x}$ Impact terhadap biaya pada proyek pembangunan Jalan Tol Layang A. P. Pettarani adalah dengan cara melakukan tinjauan kembali kerusakan yang dialami apakah kerusakan parah atau tidak. Jika parah maka harus didatangkan teknisi dari China dan untuk kerusakan di daerah sekitar pada saat proses pengerjaan bore pile, pile cap, kolom, maupun box girder adalah dengan cara Mengganti rugi serta memperbaiki kondisi sekitar seperti semula sesuai dengan perjanjian kontrak. Sedangkan untuk respon risiko pada risiko perubahan desain yang merupakan risiko yang mempunyai nilai paling besar pada tabel Probability $\mathrm{x}$ Impact terhadap waktu adalah mengajukan claim perpanjangan waktu akibat adanya perubahan desain.

Tabel 3. Probability x Impact terhadap waktu dengan risiko yang terpilih, penyebab, dan respon

\begin{tabular}{|c|c|c|c|}
\hline No & Variabel risiko & Penyebab & Respon \\
\hline 1 & A6. Tersambar petir & $\begin{array}{l}\text { Pekerjaan berisiko yang } \\
\text { berada di tempat } \\
\text { ketinggian }\end{array}$ & $\begin{array}{l}\text { Memasang alat penangkal petir di } \\
\text { tempat yang lebih tinggi dari tempat } \\
\text { para pekerja yang bekerja di } \\
\text { ketinggian. }\end{array}$ \\
\hline 2 & A7. Kebakaran & $\begin{array}{l}\text { Korslet atau keteledoran } \\
\text { pekerja yang memicu api } \\
\text { di tempat rawan } \\
\text { terhadap suhu panas }\end{array}$ & $\begin{array}{l}\text { Menyediakan APAR dan alat } \\
\text { pemadam api lainnya. }\end{array}$ \\
\hline 3 & A9. Demonstrasi & Permasalahan eksternal & $\begin{array}{l}\text { Mengganti secepatnya segala } \\
\text { property proyek yang rusak dan } \\
\text { mengatur ulang jadwal pengerjaan } \\
\text { di lapangan. }\end{array}$ \\
\hline 4 & $\begin{array}{l}\text { B9. Kerusakan peralatan mesin } \\
\text { dan perlengkapan proyek }\end{array}$ & $\begin{array}{l}\text { Kurangnya kehati-hatian } \\
\text { dalam penggunaan }\end{array}$ & $\begin{array}{l}\text { Ditinjau Kembali kerusakan yang } \\
\text { dialami. }\end{array}$ \\
\hline 5 & $\begin{array}{l}\text { C5. Tenaga kerja yang tidak } \\
\text { terampil }\end{array}$ & Kurangnya pengalaman & $\begin{array}{l}\text { Kontraktor harus lebih teliti dalam } \\
\text { menganalisa kebutuhan pekerja } \\
\text { serta memastikan keterampilan } \\
\text { pekerja untuk mencapai target. }\end{array}$ \\
\hline 6 & $\begin{array}{l}\text { C6. Kurang tersedia jumlah } \\
\text { tenaga kerja di lapangan }\end{array}$ & $\begin{array}{l}\text { Adanya desakan } \\
\text { percepatan pekerjaan }\end{array}$ & $\begin{array}{l}\text { Menambah pekerja dari luar pulau } \\
\text { yang terampil. }\end{array}$ \\
\hline 7 & $\begin{array}{l}\text { C7. Produktifitas tenaga kerja } \\
\text { yang mengakibatkan pekerja } \\
\text { kewalahanm juga kebutuhan } \\
\text { yang belum terpenuhi. }\end{array}$ & $\begin{array}{l}\text { Padatnya jadwal kerja } \\
\text { yang mengakibatkan } \\
\text { pekerja kewalahan, juga } \\
\text { kebutuhan pekerja yang } \\
\text { belum terpenuhi. }\end{array}$ & $\begin{array}{l}\text { Menganalisa kebutuhan pekerja dan } \\
\text { penambhana pekerja dan mengatur } \\
\text { ulang jadwal kerja pekerja. }\end{array}$ \\
\hline 8 & $\begin{array}{l}\text { E1. Timbulnya kemacetan di } \\
\text { sekitar lokasi proyek }\end{array}$ & $\begin{array}{l}\text { Arus lalu lintas yang } \\
\text { padat dan jalan yang } \\
\text { sempit di sekitar lokasi } \\
\text { proyek }\end{array}$ & $\begin{array}{l}\text { Bekerjasama dengan pihak terkait } \\
\text { dan menghimbau masyarakat } \\
\text { menggunakan jalur alternatif. }\end{array}$ \\
\hline 9 & $\begin{array}{l}\text { E9. Kerusakan yang terjadi di } \\
\text { daerah sekitar saat pengerjaan } \\
\text { bore pile, pilecap, kolom, } \\
\text { pierhead, dan box girder }\end{array}$ & $\begin{array}{l}\text { Lokasi proyek yang } \\
\text { berada di permukiman } \\
\text { padat penduduk }\end{array}$ & $\begin{array}{l}\text { Mengganti rugi serta memperbaiki } \\
\text { kondisi sekitar }\end{array}$ \\
\hline 10 & F2. Adanya perubahan desain & $\begin{array}{l}\text { Kondisi yang didesain } \\
\text { berbeda dengan kondisi } \\
\text { aktual }\end{array}$ & $\begin{array}{l}\text { Memperoleh pekerjaan tambah atau } \\
\text { kurang atau variasi. Mengajukan } \\
\text { klaim perpanjangan waktu. }\end{array}$ \\
\hline 11 & $\begin{array}{l}\text { G14. Ketepatan } \\
\text { konstruksi }\end{array}$ & $\begin{array}{l}\text { Kurangnya pekerja di } \\
\text { lapangan }\end{array}$ & $\begin{array}{l}\text { Penambahan pekerja yang terampil } \\
\text { dan mengerjakan pekerjaan yang } \\
\text { bisa didahulukan sambal menunggu } \\
\text { datangnya material. }\end{array}$ \\
\hline
\end{tabular}




\section{Pembahasan}

Sedangkan risiko yang dominan pada proyek berdasarkan tabel Probability $\mathrm{x}$ Impact terhadap waktu berturut-turut sesuai ranking adalah adanya perubahan desain, kerusakan peralatan mesin dan perlengkapan proyek, timbulnya kemacetan di sekitar lokasi proyek, kerusakan yang terjadi di daerah sekitar pada saat proses pengerjaan bore pile, pile cap, kolom, pier head, maupun box girder, demonstrasi/huru-hara, tenaga kerja yang tidak terampil, kurang tesedianya jumlah tenaga kerja lapangan, produktivitas tenaga kerja yang rendah, ketepatan pekerjaan konstruksi (jadwal dan kualitas), titik bore pile yang tidak tepat danbermasalah, kerusakan selama masa pemeliharaan, gempa bumi, tersambar petir, dan kebakaran.

\section{KESIMPULAN}

Didapatkan 47 variabel risiko yang relevan pada pengerjaan proyek Tol Layang A. P. Pettarani, variabel-variabel risiko tersebut terbagi dalam 7 kelompok, yaitu risiko force majeure, risiko material dan peralatan, risiko tenaga kerja, risiko kontraktual, risiko pelaksanaan, risiko desain dan teknologi, risiko manajemen.

Risiko yang dominan pada proyek berdasarkan tabel Probability $\mathrm{x}$ Impact terhadap biaya berturut-turut sesuai ranking adalah: . Kerusakan peralatan mesin dan perlengkapan proyek, kerusakan yang tejadi di daerah sekitar pada saat proses pengerjaan bore pile, pile cap, kolom, pier head, maupun box girder. Demonstrasi/huru-hara, tenaga kerja yang tidak terampil, kurang tersedianya jumlah tenaga kerja lapangan, produktivitas tenaga kerja yang rendah, kerusakan selama masa pemeliharaan, ketepatan pekerjaan konstruksi (jadwal dan kualitas), timbulnya kemacetan disekitar lokasi proyek, adanya perubahan desain.

\section{DAFTAR PUSTAKA}

[1] I. Ismiyati, R. Sanggawuri, and M. Handajani, 2020, "Penerapan Manajemen Resiko pada Pembangunan Proyek Perpanjangan Dermaga log (Studi Kasus: Pelabuhan DalamTanjung Emas Semarang)," MEDIA Komun. Tek. SIPIL, vol. 25, no. 2, p. 209, doi: 10.14710/mkts.v25i2.19467.

[2] L. Supriono, 2014, "Faktor-faktor Risiko Keterlambatan Pembangunan Proyek Infrastruktur Perdesaan Berdasarkan Waktu Perencanaan," J. Ekstrapolasi vol.7., no.1, p. 63 -72 .

[3] J. E. Latupeirissa, 2007, "Persepsi Tentang Contingency Cost Konstraktor di Indonesia," J. Teknik Sipil.vol. 7, no. 3, p. 13.

[4] A. Lokobal, M. D. J. Sumajouw, and B. F. Sompie, 2014, "Manajemen Risiko pada Perusahaan Jasa Pelaksanan Konstruksi di Propinsi Papua,"J. IImiah Media Engineering. vol.4. no.2 p. 10.

[5] T. Rustandi, 2017, "Kajian Risiko Tahap Pelaksanaan Konstruksi Proyek Peningkatan Jaringan Irigasu Bendung Leuwigoong," J. Infrastruktur . vol. 3, no. 01, p. 1-19.

[6] W. Hartono, K. R. P. D. Daluis, dan Sugiyarto, 2015, "Analisis Risiko Konstruksi Struktur Atas Dengan Metode Analytical Hierarchy Process," J. Matriks Teknik Sipil, vol.3, no.3, p. 879 885.2015 